\title{
Recursos humanos: imprescindibles para el logro de la equidad en salud
}

\author{
GIORGIO SOLIMANO(1)
}

Hace algunos meses, se realizó en Barcelona la reunión final del Grupo Coordinador del proyecto "Joint Learning Initiative on Human Resources for Health and Development". Este proyecto internacional fue iniciado por la Fundación Rockefeller hace dos años y a él se han sumado importantes instituciones como la Organización Mundial de la Salud, Universidades, el Banco Mundial y Agencias de Cooperación Bilateral. Su propósito es promover y avanzar en el logro de la equidad en salud mediante el fortalecimiento de la producción, una adecuada distribución y el empoderamiento de los recursos humanos para salud en los países en desarrollo.

Sus objetivos estratégicos pueden resumirse en identificar y analizar las diferentes dimensiones de la crisis de los recursos humanos en salud, como evidencia para formular las estrategias que se requieren para abordar esta crisis en forma efectiva, y desarrollar un esfuerzo de abogacía frente a los tomadores de decisiones locales, nacionales e internacionales.

Esta iniciativa ha convocado a más de 100 profesionales con reconocida capacidad de liderazgo de diferentes países, quienes, organizados en siete grupos, han consultado extensamente, elaborado o comisionado más de 50 trabajos y escuchado la voz tanto de los trabajadores como de los usuarios de los servicios de salud. Me ha correspondido coordinar el Grupo "Oferta de Recursos Humanos" cuya misión fue definida como "identificar y mapear los mecanismos y modalidades de educación y capacitación existentes a nivel mundial, y formular recomendaciones y estrategias que permitan lograr mayor relevancia, innovación y equidad en la formación de los recursos humanos requeridos en salud".

\section{La doble crisis}

Después de un siglo de avances espectaculares en salud, el siglo XXI se inicia con una doble crisis: dramáticos retrocesos en salud y débiles respuestas para revertirlos a nivel de grandes conglomerados de población, problemas que si no son atendidos oportunamente influirán negativamente en el curso de la salud global por el siglo entero.

El VIH/SIDA y la disparidad entre países ricos y pobres, son sólo algunas de las amenazas evidentes en un mundo crecientemente interdependiente en salud. Pero, al mismo tiempo, constituyen un desafío ético y un imperativo moral para la acción, reconociendo que se abren oportunidades para derrotarlos.

Por otra parte, la evidencia muestra que los profesionales capacitados migran de los países pobres a los ricos y del sector público al privado, aumentando la mala distribución y el desequilibrio. Hay una concentración de profesionales en las capitales. Un claro ejemplo es que hoy trabajan más médicos malawíes en Manchester (Inglaterra) que en Malawi. Como esa nación africana, muchos países de bajos ingresos están perdiendo sus equipos de salud en cantidades alarmantes.

Lo que ocurre es que el recurso humano es considerado de baja prioridad. Los gobiernos y los donantes los consideran un gasto, no

(1) Escuela de Salud Pública. Facultad de Medicina. Universidad de Chile, gsolimano med.uchile.cl 
una inversión. Las políticas de ajuste estructural han puesto techo al número de personas y a los salarios, y los recursos destinados a invertir en formación y capacitación de mejor calidad son insuficientes. Los proyectos, con fondos nacionales o internacionales, captan los talentos locales disponibles, pero no invierten en la gente a largo plazo; financian la asistencia técnica y entrenamiento a corto plazo, a menudo fragmentados, sin una visión estratégica, coordinación ni planes de desarrollo.

Sin embargo, está demostrado que la inexistencia de recursos humanos capacitados es -quizás- el mayor impedimento para la provisión de servicios de salud adecuados y oportunos. El camino para alcanzar "Salud para Todos" y las reformas recientes en salud, que no reconocieron la importancia ni priorizaron lo suficiente los recursos humanos, son ejemplos palpables de ello. Sin embargo, el clima creado, entre otros, por el establecimiento de las Metas de Desarrollo para el Milenio con el consiguiente incremento en los fondos para enfrentar algunas de las mayores enfermedades en el mundo, dan cuenta de que -finalmente- la gestión, planeación y desarrollo de recursos humanos está comenzando a recibir la atención que merece.

Para capitalizar estas oportunidades, la comunidad global debe abocarse a movilizar y fortalecer los recursos humanos para la salud, distribuir mejor la carga laboral resultante de los problemas emergentes y dotar de nuevas habilidades a los trabajadores de la salud. Anticiparse, responder oportunamente y revertir estas crisis requiere -por una partesistemas de salud modernos y eficientes, y -por otra- instituciones formadoras, principalmente universidades, concientes de los problemas y capaces de responder en forma efectiva $y$ oportuna.

Un proyecto de este alcance y envergadura es altamente relevante y concuerda con el proceso de planificación estratégica que lleva a cabo nuestra Facultad de Medicina, cuyo Plan de Desarrollo 2001-2005 define la misión como: "Formar profesionales de la salud de gran responsabilidad, con sólida formación ética, espíritu de servicio y compromiso con el bienestar de la comunidad para contribuir a elevar la calidad de vida de la población".

\section{Hacia reformas efectivas}

El aumento en la expectativa de vida en el último siglo fue favorecido, en gran medida, por la transformación de la fuerza de trabajo en un conjunto de profesiones sustentadas en el perfeccionamiento científico, formalmente organizadas, bien entrenadas y bien compensadas. En otras palabras, los logros en salud, incluyendo programas efectivos de control de enfermedades, fueron construidos con base en estrategias de desarrollo de los recursos humanos exitosas.

Es que los centros de salud, hospitales y clínicas y servicios de salud son tan buenos como la gente que los conforma. Los recursos humanos son el vínculo que amalgama todos los esfuerzos para superar las crisis y alcanzar las Metas de Desarrollo del Milenio. Sólo cuando las iniciativas de alto nivel, el financiamiento y las tecnologías estén acompañados de una importante inversión en las personas, las fórmulas para mejorar la salud de la población estarán completas.

En cuanto a las reformas en salud, la participación de la fuerza de trabajo es especialmente importante: una persona motivada puede ser líder e implementar innovaciones; mal tratada, puede constituir un serio obstáculo. De hecho, no se reportan reformas en salud exitosas sin la participación de los trabajadores. Ellos deben ser aliados estratégicos en la provisión de servicios de salud, pues son quienes gestionan todos los demás recursos (financiamiento, infraestructura, tecnología, conocimiento, información). Descuidar al recurso humano es, en esta perspectiva, malgastar los otros.

Así las cosas, una buena gestión de los recursos humanos puede actuar como catalizador para acelerar el progreso en salud. En esta perspectiva estratégica, este proyecto de alcance mundial ha generado un conjunto de recomendaciones para ser aplicadas tanto a nivel comunitario, como de los países y a nivel global. Muchas de ellas están dirigidas a las instituciones académicas y se relacionan directamente con el ámbito de nuestras 
responsabilidades académicas.

Las recomendaciones generales se refieren a aspectos como la gestión del conocimiento y el mejoramiento de la educación de pre y postgrado, así como la capacitación en servicio; el fortalecimiento de los liderazgos; las alianzas con los sectores no gubernamentales y privado; la acción comunitaria y la movilización social, además de estrategias relacionadas con el aprovechamiento de experiencias innovadoras y la adopción de medidas para reducir la migración del personal de salud.

En el ámbito de la Oferta/Formación de Recursos Humanos, los "mensajes clave" que emergen del trabajo del grupo se pueden resumir en:

- Existe insuficiencia o falta de relación entre la demanda y la oferta de recursos humanos.

- Los problemas detectados en la oferta de recursos humanos adecuados no son de exclusiva responsabilidad de las instituciones formadoras, ya que los proveedores de servicios también contribuyen a ellos.

- En la práctica, no se reconoce que las condiciones de salud de las personas y las poblaciones, junto con los avances científicos y tecnológicos, están fuertemente influenciados por factores sociales, lo que requiere fortalecer una perspectiva de formación más amplia.
- La complejidad del mundo moderno asociada a problemas específicos de salud, requiere de un nuevo profesional con conocimientos y capacidad para ejercer liderazgo, tomar decisiones, trabajar en equipo, comunicar y difundir el conocimiento, entre otros.

- Experiencias innovadoras en la formación de recursos humanos son poco conocidas y no se difunden. Es necesario asignar recursos financieros para resolver estos problemas en beneficio de la comunidad académica internacional.

- En la perspectiva de la globalización, la ayuda internacional puede contribuir significativamente a mejorar las condiciones de salud de vastos grupos de población. Para ello se requiere que los donantes trabajen con las instituciones nacionales, contribuyan a fortalecer las capacidades institucionales y faciliten el intercambio de experiencias a nivel regional. Un buen ejemplo de esto son los Observatorios de Recursos Humanos en Salud desarrollados en varios países latinoamericanos.

El informe final será conocido en septiembre y servirá de guía para enfrentar la crisis existente. En el intertanto, quienes deseen informarse sobre el proyecto lo pueden hacer en el portal: www.globalhealthtrust.org

Usted puede comentar éste y otros artículos publicados en la Revista Chilena de Salud Pública, enviando un correo electrónico a revistasp@med.uchile.cl 